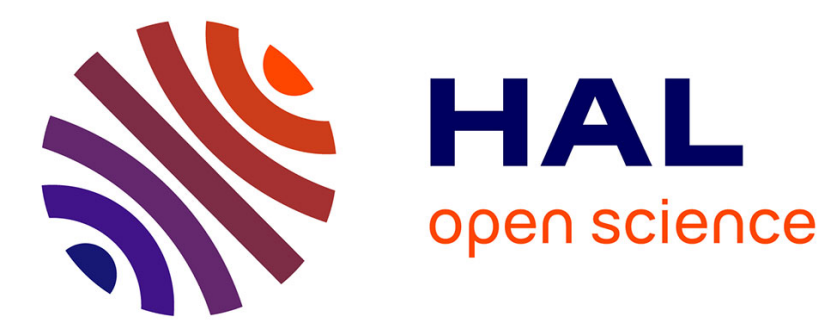

\title{
Seismic Site-City Interaction: Main Governing Phenomena through Simplified Numerical Models
}

\author{
A. Kham, Jean François Semblat, Pierre-Yves Bard, Patrick Dangla
}

\section{To cite this version:}

A. Kham, Jean François Semblat, Pierre-Yves Bard, Patrick Dangla. Seismic Site-City Interaction: Main Governing Phenomena through Simplified Numerical Models. Bulletin of the Seismological Society of America, 2006, 96 (5), pp.1934-1951. 10.1785/0120050143 . insu-00267062

\section{HAL Id: insu-00267062 \\ https://hal-insu.archives-ouvertes.fr/insu-00267062}

Submitted on 20 Mar 2009

HAL is a multi-disciplinary open access archive for the deposit and dissemination of scientific research documents, whether they are published or not. The documents may come from teaching and research institutions in France or abroad, or from public or private research centers.
L'archive ouverte pluridisciplinaire HAL, est destinée au dépôt et à la diffusion de documents scientifiques de niveau recherche, publiés ou non, émanant des établissements d'enseignement et de recherche français ou étrangers, des laboratoires publics ou privés. 


\title{
Seismic Site-City Interaction: Main Governing Phenomena Through Simplified Numerical Models
}

\author{
By Marc Kham ${ }^{* \dagger}$, Jean-François Semblat ${ }^{* 1}$, Pierre-Yves Bard** and Patrick \\ Dangla*** \\ * Laboratoire Central des Ponts et Chaussées. 58, Bd Lefebvre, 75732 Paris Cedex \\ 15, France \\ ** LCPC/LGIT, University of Grenoble, France \\ *** LCPC/LMSGC (Institut Navier), 2 allée Kepler, 77420 Champs-sur-Marne, \\ France \\ ${ }^{\dagger}$ currently at EDF R\&D, 1, avemue du Général de Gaulle, F-92141 Clamart, France
}

\begin{abstract}
This work focuses on the analysis of the multiple interactions between soil layers and civil engineering structures in dense urban areas submitted to a seismic wave. To investigate such phenomena, called Site-City Interaction $(S C I)$ herein, two simplified site-city configurations are considered: a homogeneous, periodically spaced city and a heterogeneous, non-periodically spaced city, both on a constant depth basin model. These 2D BEM models are subjected to a vertically incident plane SH Ricker wavelet. A parametric study of the city parameters (density of buildings and their natural frequencies) and the thickness of the basin is carried out to characterize the SCI, and to investigate its sensitivity to some governing parameters. The following parameters are analysed: building vibrations, induced ground motion, ground motion perturbations inside and outside the city, spatial coherency and kinetic energy of the "urban wavefield". It results that a so-called "site-city resonance" is reached when the soil fundamental frequency and structures eigenfrequencies coincide; building vibrations and ground motion are then significantly decreased and the spatial coherency of the urban field is also strongly modified. Building density and city configuration play a crucial role in the energy distribution inside the city.
\end{abstract}

\footnotetext{
${ }^{1}$ Corresponding author : semblat@1cpc.fr
} 


\section{What Does Site-City Interaction Mean?}

Several experimental evidences have already shown that the vibrations transmitted from a building to the ground may propagate over large distances. One of the first examples is the Millikan library experiment by Jennings (1970), who recorded a wave generated by the forced vibration of the building up to $10 \mathrm{~km}$ away. Another example concerns the 1985 Michoachan Mexico earthquake: the urban area suffered some particularly long and strong ground motions. According to some researchers (Wirgin \& Bard, 1996; Guéguen et al., 2002; Guéguen, 2000), the large amplitude of the signals and their particularly long duration exhibiting beating phenomena may be due to an interaction with the built environment itself. As a matter of fact, in the case of Mexico City, the characteristics of the alluvial layers and the buildings were favourable for soil/structure coupling and might have resulted in a significant global effect because of the built environment of the city . The ground motion amplification by soil/structure interaction has been confirmed by many observations. Erlingsson and Bodare (1996; Erlingsson, 1999) analyzed the ground motion during a rock concert at Ullevi stadium, in Gothenburg (Sweden). The public monotonic jumps were amplified by the ground and induced the collapse of the neighbouring structures. The authors concluded that the human jumps matched the soil resonance frequency at $2 \mathrm{~Hz}$ and the vibrations were therefore easily transmitted to the structures.

Since then, several works addressed the topic of the so-called site-city interaction (SCI). For example, Wirgin and Bard (1996)considered two-dimensional numerical models to describe the diffraction pattern of surface waves due to influence of buildings, while Tsogka and Wirgin (2003) assessed their impact on buildings. Clouteau and Aubry (2001) and Clouteau et al. (2002) performed 3D computations (boundary element method) to characterize SCI in the case of Nice (France) and Mexico City. Other authors have tried to give an analytical description of SCI. For instance, Guéguen et al. (2002) described the global city effect by adding the single contribution of each building represented by a single oscillator, while the model proposed by Boutin and Roussillon (2004) accounts for the multiple interactions between buildings. Since the cumulative single soil-structure interaction is obviously an approximation of the global site-city effect, Clouteau et al. (2002)analysed the domain of validity: mainly short wavelengths. Finally, some experimental studies have also been conducted to assess SCI. Let us cite the Volvi experiment made by Guéguen et al., (2000), who recorded the wavefield radiated by a reduced-scale structure in the Volvi EuroSeisTest site. Chávez-García and Cárdenas-Soto (2002) in Mexico City highlighted the influence of one tall building through the use of $\mathrm{H} / \mathrm{V}$ spectral ratios. Chazelas et al. (2003) observed interactions between structures through the soil with reduced scale centrifuge experiments (Semblat and Luong, 1998).

All the above mentioned references point out the need for further investigations on SCI. Indeed, one cannot consider today to have a clear understanding yet of the basic effects of SCI, because either of the complexity of the site-city models (3D effects, irregular city) or of the restrictive assumptions (homogenization of the site-city medium). The present work aims at the characterization of the main features of the SCI and their governing parameters. Simplified models of both soil and city are considered in 2D numerical simulations based on the boundary element method. The influence of multiple SCI on the various characteristics of the ground motion and the building responses is discussed through a parametric study mainly considering the basin thickness and the city configuration (building density, regularity, homogeneity).

\section{The site-city models}

The basic objective is to understand the main phenomena involved in SCI, which implies performing comprehensive sensitivity studies. In order to limit the number of governing parameters and to keep the computation time at an affordable level, we considered only two-dimensional site-city models. 
The soil consists of a $2 \mathrm{D} 2.4 \mathrm{~km}$ wide, sediment-filled valley, with a trapezoidal geometry as depicted in Figure 1. The central flat, horizontally layered part is $2 \mathrm{~km}$ wide, and is closed at each edge with a linear ramp of $200 \mathrm{~m}$ width. Since the valley thickness, H, remains very small compared to its width, the valley response is expected to be dominated by the 1D response of the surface layer. Nevertheless, valley edges generate a certain amount of surface waves, which induce late arrivals in the central part of the basin and add arrivals to the surface ground motion.

Two city configurations are considered on the basin. The first one consists of $\mathrm{N}$ identical buildings, regularly spaced over a distance $\mathrm{L}$ and located in the valley centre. The distance $\mathrm{L}$ is kept constant, equal to $500 \mathrm{~m}$, thus changing the number of buildings $\mathrm{N}$ is equivalent to modifying the building density. The second configuration is composed of two different building types arbitrarily arranged with a variable spacing. The configuration of this irregular city model is also displayed in Figure 1. In the numerical model, buildings are represented by homogeneous elastic blocks and are characterized by homogeneous mechanical properties. These properties are listed in Table 1 for the two canonical building types denoted B1S and B2S. This terminology refers to the first soil/structure shear resonance frequency: the shear stiffness was tuned to get $1 \mathrm{~Hz}$ and $2 \mathrm{~Hz}$, respectively, for the natural frequency of B1S and B2S standing over a half-space with the same mechanical properties as the basin.

To compute the site and city response, we used the boundary element method (Dangla, 1988; Dangla et al., 2005). This method was fully described for instance in Bonnet (1999). Both soil and city models are described by boundary elements. The boundary conditions applied to the interface between each building and the soil are continuity of displacement and stress.

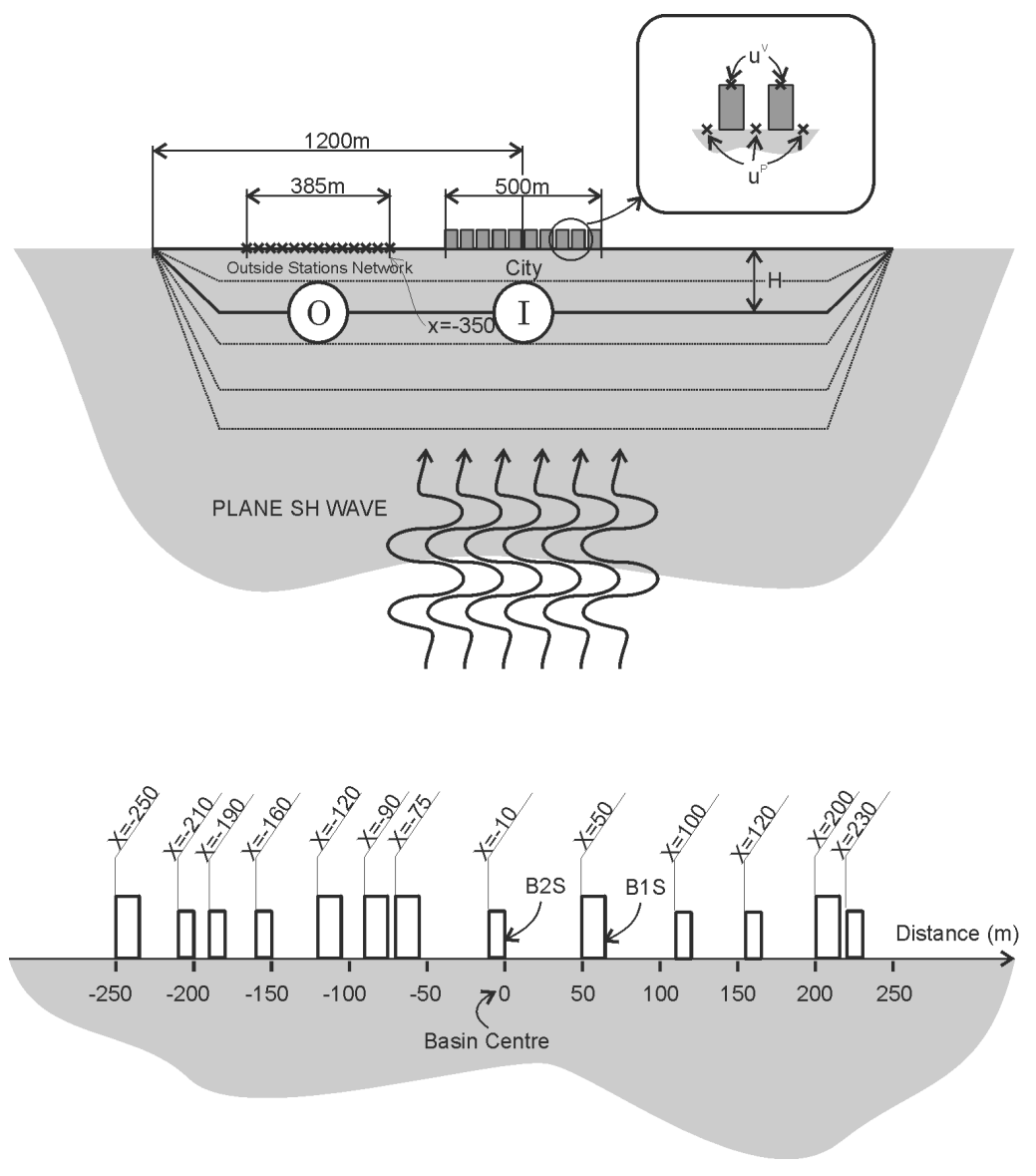

Figure 1: Site-City model (top) and irregular city model (bottom). 


\begin{tabular}{|c|c|c|}
\cline { 2 - 3 } \multicolumn{1}{c|}{} & LAYER & BEDROCK \\
\hline DENSITY & $1800 \mathrm{~kg} / \mathrm{m}^{3}$ & $2000 \mathrm{~kg} / \mathrm{m}^{3}$ \\
\hline$Q_{\mathbf{s}}$ & 25 & 100 \\
\hline $\mathbf{V}_{\mathbf{s}}$ & $200 \mathrm{~m} / \mathrm{s}$ & $1000 \mathrm{~m} / \mathrm{s}$ \\
\hline
\end{tabular}

\begin{tabular}{|c|c|c|}
\hline Buildings & B1S & B2S \\
\hline HEIGHT & $40 \mathrm{~m}$ & $30 \mathrm{~m}$ \\
\hline WIDTH & $15 \mathrm{~m}$ & $10 \mathrm{~m}$ \\
\hline DENSITY & $250 \mathrm{~kg} / \mathrm{m}^{3}$ & $250 \mathrm{~kg} / \mathrm{m}^{3}$ \\
\hline $\mathbf{Q s}_{\mathbf{s}}$ & 10 & 10 \\
\hline $\mathbf{f}^{\mathbf{B}}$ & $1 \mathrm{~Hz}$ & $2 \mathrm{~Hz}$ \\
\hline
\end{tabular}

Table 1: Mechanical properties of the soil (left) and city models (right).

The site-city model is submitted to a vertical plane $\mathrm{SH}$ wave. In the time domain, the excitation is a Ricker waveform of second order with amplitude $\mathrm{u}_{0}$ and central frequency $\mathrm{f}^{\mathrm{R}}$ :

$$
R(t)=u_{0}\left(2 a^{2}-1\right) \exp \left(-a^{2}\right)
$$

with $\mathrm{a}=\pi\left(\mathrm{t}-\mathrm{t}_{\mathrm{S}}\right) / \mathrm{t}_{\mathrm{P}}$, where $\mathrm{t}$ is the time, $\mathrm{t}_{\mathrm{S}}$ the peak position in time and $t_{\mathrm{P}}$ the characteristic period of the signal (frequency: $\mathrm{f}^{\mathrm{R}}=1 / \mathrm{t}_{\mathrm{P}}$ ).

\section{Results for a Regular City}

\section{Description of the site-city model}

In order to understand the main features of site-city interaction, we first considered the regular sitecity model (periodically spaced B2S buildings), and investigated the sensitivity of its response to building density and basin thickness:

- The building density $\theta=\mathrm{N} \times \mathrm{B} / \mathrm{L}$, where $\mathrm{B}$ is the building width, is equal to $\theta=0.02 \times \mathrm{N}$. In our study, we took $\mathrm{N}=10,16,25$ and 33 , corresponding to $\theta=0.2,0.32,0.5$ and 0.66 . In the following, we will refer to either $\mathrm{N}$ or $\theta$.

- The basin thickness $\mathrm{H}$ is related to the free-field soil resonance frequency $\mathrm{f}_{0}{ }^{\mathrm{S}}$ through the approximation $\mathrm{f}_{0}{ }^{\mathrm{S}} \approx \mathrm{V}_{\mathrm{S}} / 4 \mathrm{H}$, where $\mathrm{V}_{\mathrm{S}}$ is the shear wave velocity. According to previous studies, the site-city interaction is partly controlled by the relation between $\mathrm{f}_{0} \mathrm{~S}$ and the building resonance frequency $\mathrm{f}^{\mathrm{B}}=2 \mathrm{~Hz}$. Therefore, in order to consider $\mathrm{f}_{0} \mathrm{~S} / \mathrm{f}^{\mathrm{B}}$ values of $2,1,0.75,0.5$ and 0.33 , computations were performed for thickness values $H$ of $12.5 \mathrm{~m}, 25 \mathrm{~m}, 33 \mathrm{~m}, 50 \mathrm{~m}$ and $75 \mathrm{~m}$, respectively.

- We choose the Ricker central frequency $\mathrm{f}^{\mathrm{R}}=\mathrm{f}^{\mathrm{B}}=2 \mathrm{~Hz}$.

In order to characterize the site-city response, we first computed the genuine "free-field" response $\mathrm{u}^{\mathrm{FF}}$, corresponding to $\theta=0$ (no building). Then, for each "site-city" model, we computed both the relative building motion $\mathrm{u}^{\mathrm{V}}=\mathrm{u}^{\mathrm{T}}-\mathrm{u}^{\mathrm{B}}$ as the difference between top $\left(\mathrm{u}^{\mathrm{T}}\right)$ and base $\left(\mathrm{u}^{\mathrm{B}}\right)$ displacements, and the perturbed wavefield $u^{\mathrm{P}}=\mathrm{u}^{\mathrm{S}}-\mathrm{u}^{\mathrm{FF}}$ as the difference between the motion $\mathrm{u}^{\mathrm{S}}$ computed at ground surface and the freefield motion $u^{\mathrm{FF}}$ at the same locations. This latter comparison was performed for 
two areas. Inside the city (area I), the ground responses $\mathrm{u}^{\mathrm{S}}$ or $\mathrm{u}^{\mathrm{P}}$ were computed for all points located at mid-distance between two neighbour buildings. Outside the city (area $\mathbf{O}$ ), the ground responses were computed along a $385 \mathrm{~m}$ long array, starting $350 \mathrm{~m}$ from the valley centre, i.e., $100 \mathrm{~m}$ from the closest building (Fig.1)

\section{Overall features of the city response}

The average displacements $u^{\mathrm{V}}$ and $\mathrm{u}^{\mathrm{P}}$, together with their variability (average minus and plus one standard deviation), for area $\mathbf{I}$, are displayed in Figure $\mathbf{2}$ for different building densities $\theta$ and a fixed thickness $\mathrm{H}=25 \mathrm{~m}$, and in Figures $\mathbf{3}$ and $\mathbf{4}$ for different basin thicknesses $\mathrm{H}$ and a fixed number of buildings $\mathrm{N}=33$. Obviously, the city response is influenced by both the building density and the basin thickness. The most striking results are:

- For a larger building density (Fig.2, top), the amplitude and duration of buildings vibrations decrease. This point is obvious in the corresponding transfer functions (plotted for each individual building), which become clearly lower than the single building response: the large fundamental peak tends to split into multiple lower peaks due to the multiple interactions between buildings. The coincidence of the resonance frequencies between the buildings and the soil favour these interactions. When this happens, the strengthening of the multiple interactions by a growing number of buildings tends to hinder the building free oscillations, resulting in amplitude decrease. On the contrary, the larger building density increases the magnitude of the perturbed wavefield on the ground (Fig. 2, bottom). Their corresponding transfer functions exhibit a clear peak at $2 \mathrm{~Hz}$, the common soil and building frequency.

- As shown in Figure 3, the ground motion perturbations $\mathrm{u}^{\mathrm{P}}$ exhibit a much larger sensitivity to thickness than the buildings relative vibrations $\mathrm{u}^{\mathrm{V}}$. While the buildings response has always its peak at $2-3 \mathrm{~Hz}$ whatever the basin thickness (Fig.3), the spectrum of the ground motion perturbations follow the site "free-field" frequencies (Fig.4), and their amplitudes depend on the proximity between the building frequency $(2 \mathrm{~Hz})$ and the soil frequencies. It is largest (up to 10 for $\theta=0.66$ ) for $\mathrm{H}=25 \mathrm{~m}$, intermediate for $\mathrm{H}=33 \mathrm{~m}$ and $75 \mathrm{~m}$, and smallest (roughly divided by $3-4$ ) for $\mathrm{H}=12.5 \mathrm{~m}$ and $50 \mathrm{~m}$. This indicates that the perturbations are due to both the building vibration and to the soil response. The influence of the city on the freefield motion becomes strong when both buildings and soil resonance frequencies coincide. This effect is well known to favour soil/structure coupling, but what is not so obvious is how much a set of buildings can modify the freefield motion by multiple interactions between one another. This question is tackled in the next paragraph.

- The ground response modifications induced by the SCI inside the city may also contaminate the ground motion outside the city, because of the wavefield radiated from the buildings (Figure 5). A surface wave train emitted from the city and propagating outwards is clearly identified. The amplitude of the radiated wavefield is maximum for a basin thickness $\mathrm{H}=25 \mathrm{~m}$, i.e., when the site and city strongly interfere, and waves back-radiated from buildings are strongly transmitted to the soil by soil/structure coupling, and trapped in the surficial layer. 

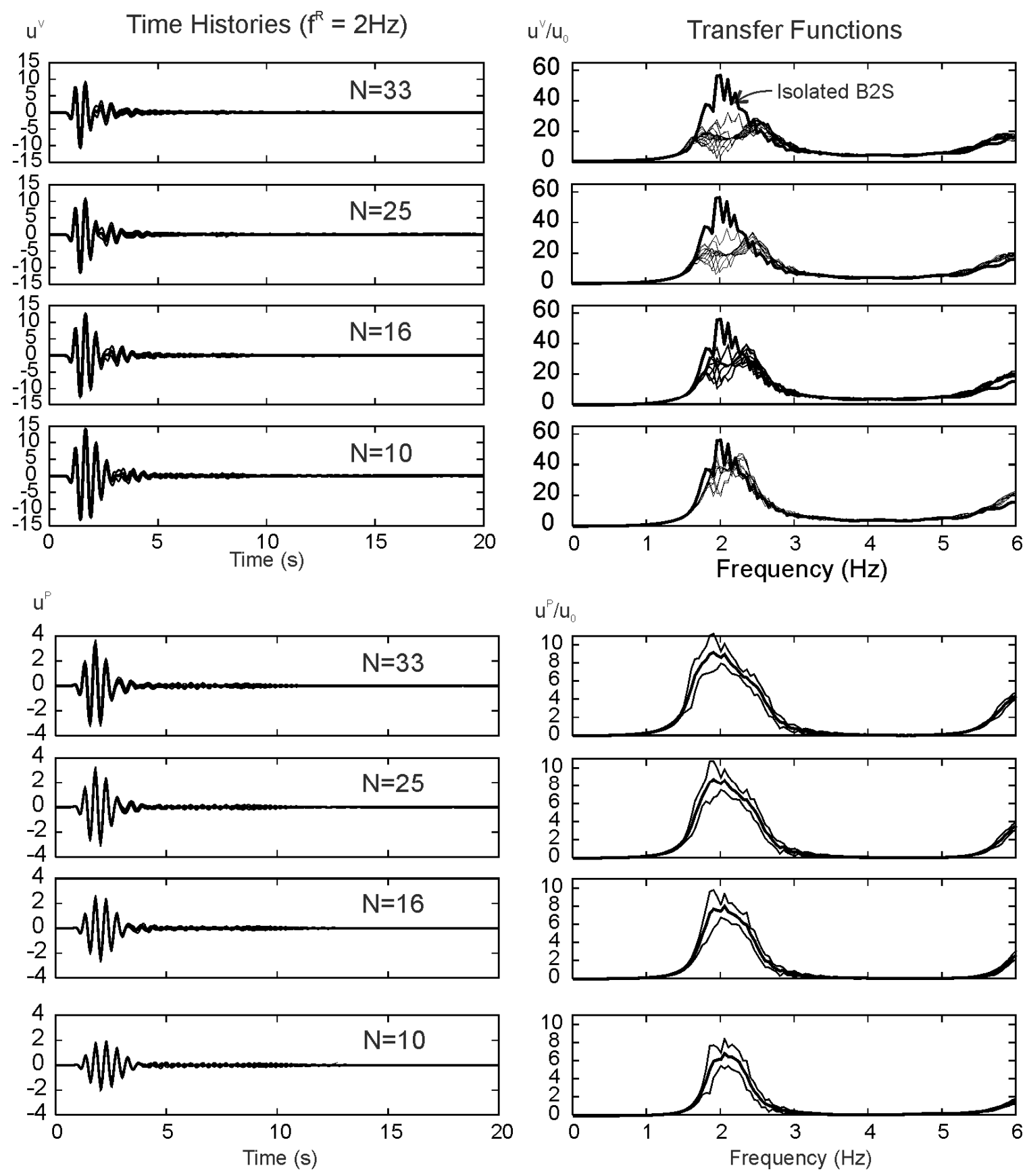

Figure 2: Time solutions (left) and transfer functions (right) for the B2S regular city model for thickness $\mathrm{H}=25 \mathrm{~m}$, various numbers of buildings $\mathrm{N}$ and a Ricker wavelet of central frequency $\mathrm{f}^{\mathrm{R}}=$ $2 \mathrm{~Hz}$ : Buildings vibrations (top). Ground perturbations between the buildings (bottom). Solutions correspond to an average over the buildings number, with plus and minus one standard deviation. For the transfer functions of building vibrations (right), the individual transfer function of each building are displayed since they are more relevant. 

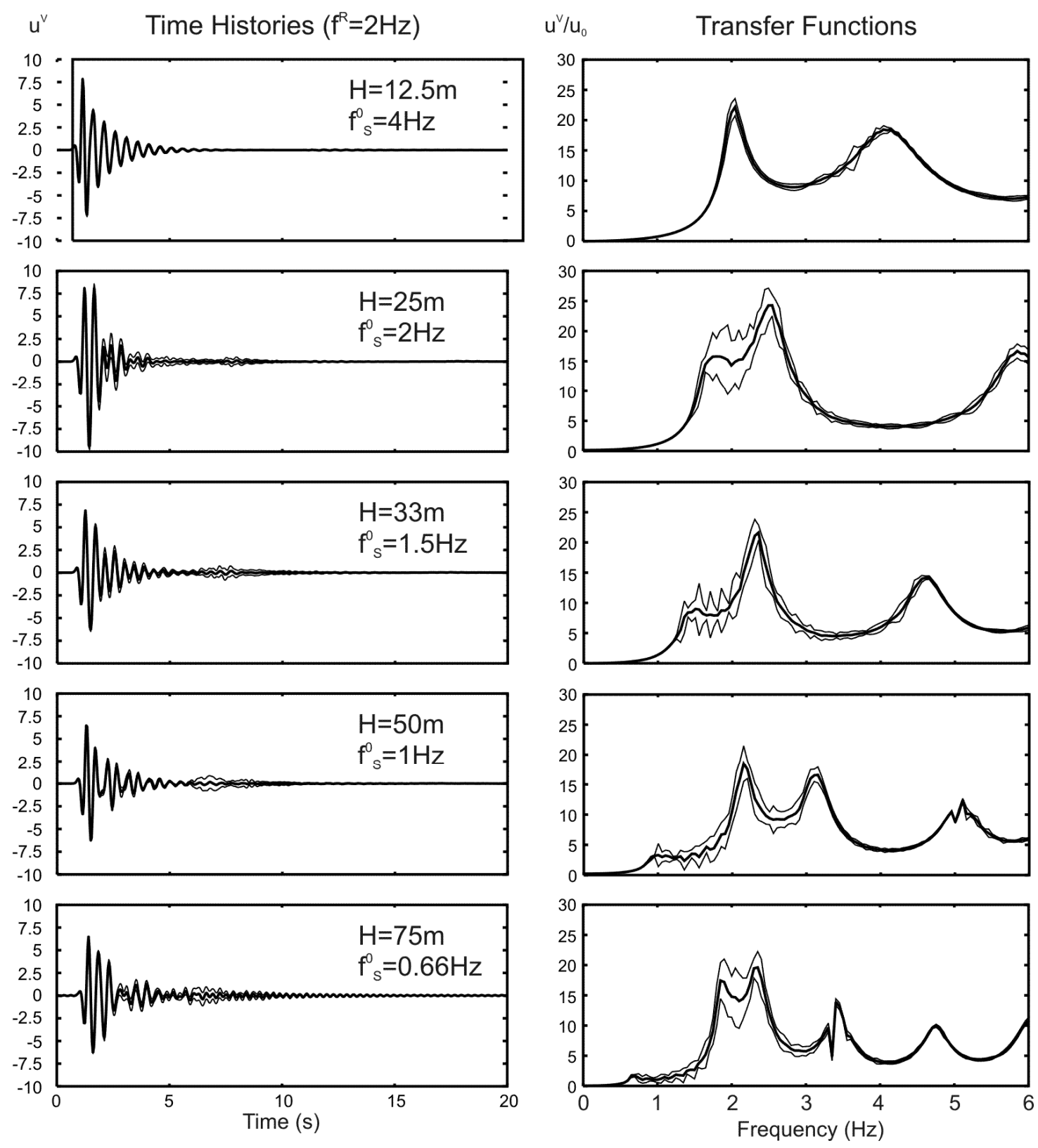

Figure 3: Buildings vibrations (left) and corresponding transfer functions (right) in the regular city model for a number of buildings $\mathrm{N}=33$, various thicknesses $\mathrm{H}$ and a Ricker wavelet of central frequency $\mathrm{f}^{\mathrm{R}}=2 \mathrm{~Hz}$. 

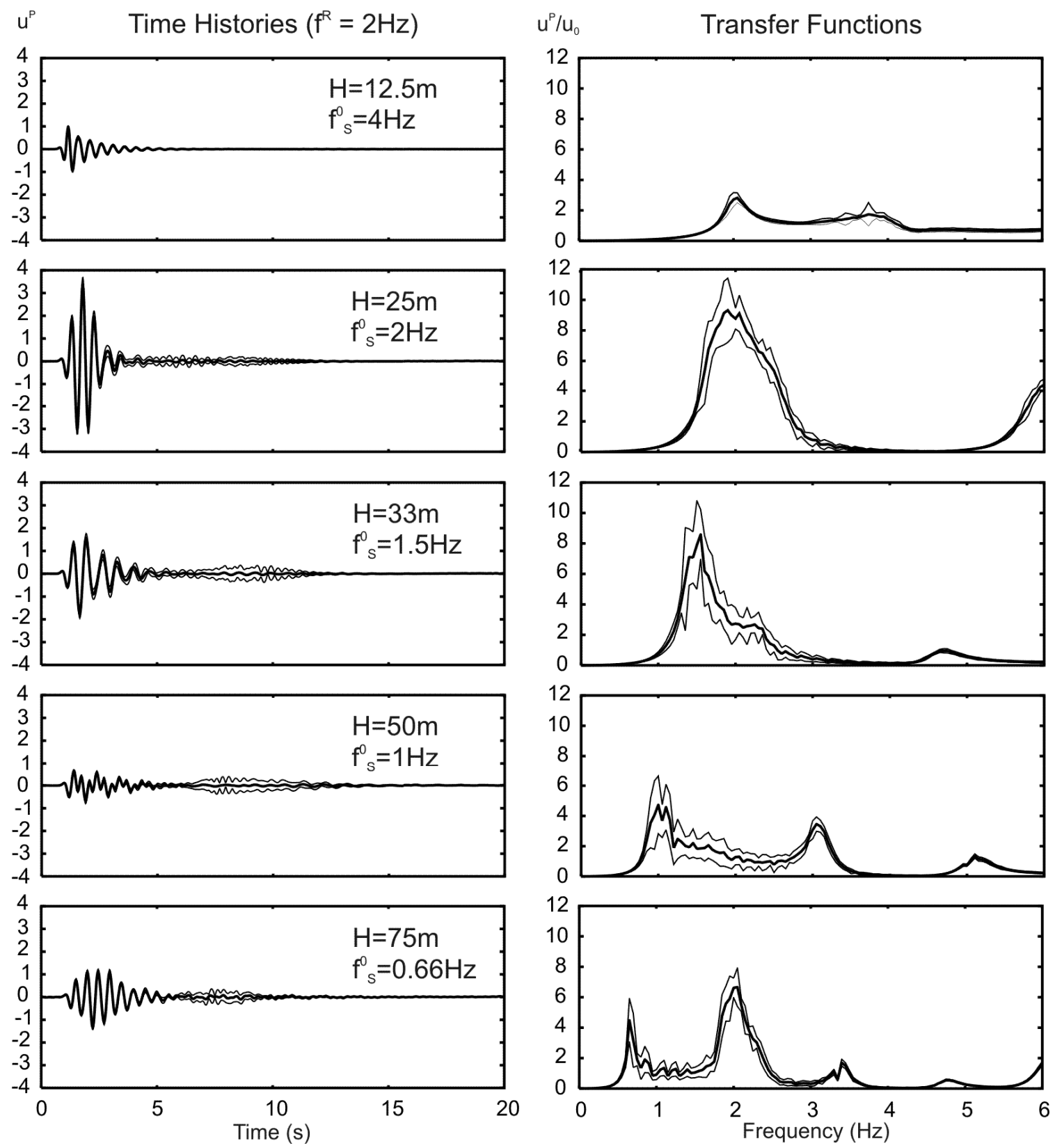

Figure 4: Ground perturbations and corresponding transfer functions between the buildings in the regular city model for a number of buildings $\mathrm{N}=33$, various thicknesses $\mathrm{H}$ and a Ricker wavelet of central frequency $\mathrm{f}^{\mathrm{R}}=2 \mathrm{~Hz}$. 

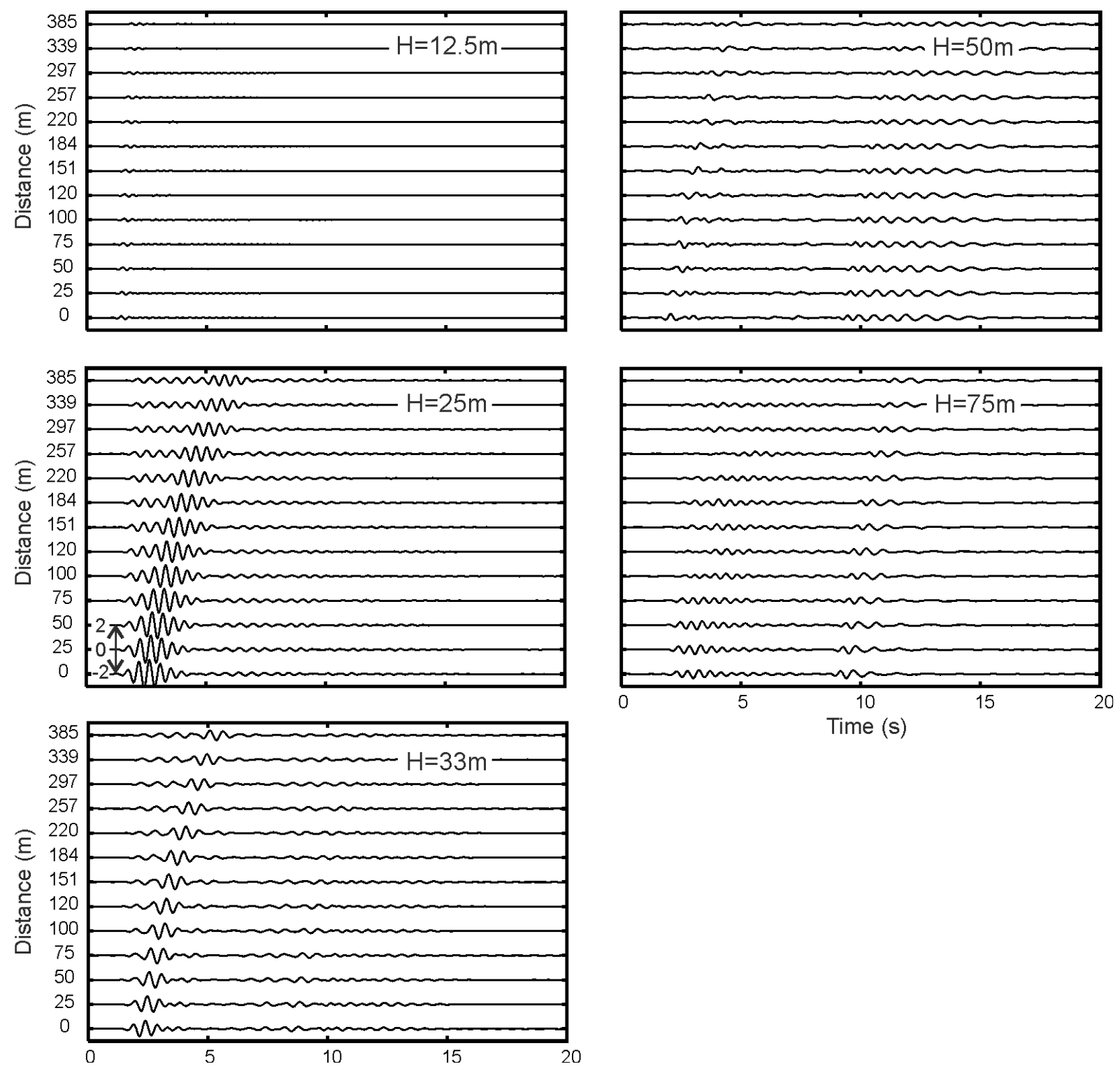

Figure 5: Wavefield radiated outside (area $\mathbf{O}$ ) the regular city model for a number of buildings $\mathrm{N}=33$, various thicknesses $\mathrm{H}$ and a Ricker wavelet of central frequency $\mathrm{f}^{\mathrm{R}}=2 \mathrm{~Hz}$. Wave amplitude scale corresponds to 2 from one trace to another. We recall that the incident wave amplitude is $A_{0}=2$.

\section{Modifications on ground motion}

Ground shaking energy in the city. In order to give a global assessment of the site-city interaction, we study the variation of ground motion energy inside and outside the city. We define the ground kinetic energy as :

$$
E(x)=\frac{1}{T} \int_{0}^{T}\left[\frac{d u}{d t}(x, t)\right]^{2} d t
$$

where $\mathrm{T}$ is the signal duration, $\mathrm{u}$ the displacement and $\mathrm{t}$ the time. This energy $\mathrm{E}(\mathrm{x})$ may then be spatially averaged over a given area, and may be computed for the total ground motion field $u$, and for the perturbed ground motion $\mathrm{u}^{\mathrm{P}}$.

Figure 6 displays the average energies computed with equation 1 in two areas (inside the city, area $\mathbf{I}$, and outside the city, area $\mathbf{O}$ ) as a function of the basin thickness $\mathrm{H}$ and for various building densities. 
The most striking - and interesting - result is that the total ground motion energy inside the city is systematically lower than the free-field energy. This decrease is controlled by two factors:

1. the ratio between the soil and building frequencies: the closer these frequencies, the larger the reduction (i.e., in the present case, for $\mathrm{H}=25 \mathrm{~m}$ and $\mathrm{H}=75 \mathrm{~m}$ )

2. the building density: the larger the building density, the larger the decrease.

This energy decrease reaches $50 \%$ in the "optimal case", i.e., for the largest number of buildings $(\mathrm{N}$ $=33$ ) and for coinciding resonance frequencies $(\mathrm{H}=25 \mathrm{~m})$. This decrease is consistently associated to a symmetrical increase of the perturbations energy which reaches $80 \%$ for $\mathrm{H}=25 \mathrm{~m}$ and $\mathrm{N}=33$. This is very important: while designing a single building on a soft soil with a natural frequency coinciding with the soil frequency is never recommended, installing a dense building array may have a rather beneficial effect on ground and building motion. This energy decrease due to site-city effect is also consistent with several previous numerical studies (Clouteau and Aubry, 2001, Clouteau et al., 2002, Semblat et al., 2002a, 2002b, Boutin and Roussillon, 2004)] or even instrumental results (ChávezGarcía and Cárdenas-Soto, 2002). Effect (1) is related to the soil/structure dynamic properties, while effect (2) is related to the cumulated mass of the buildings, and may be called "inertial effect". This second effect may be of the same importance in the energy decrease as the dynamic resonance (for example, we have similarly $\mathrm{E} / \mathrm{E}^{\mathrm{FF}}=75 \%$ for $\mathrm{N}=16$ at $\mathrm{H}=25 \mathrm{~m}$, and $\mathrm{N}=25$ at $\mathrm{H}=50 \mathrm{~m}$ ).
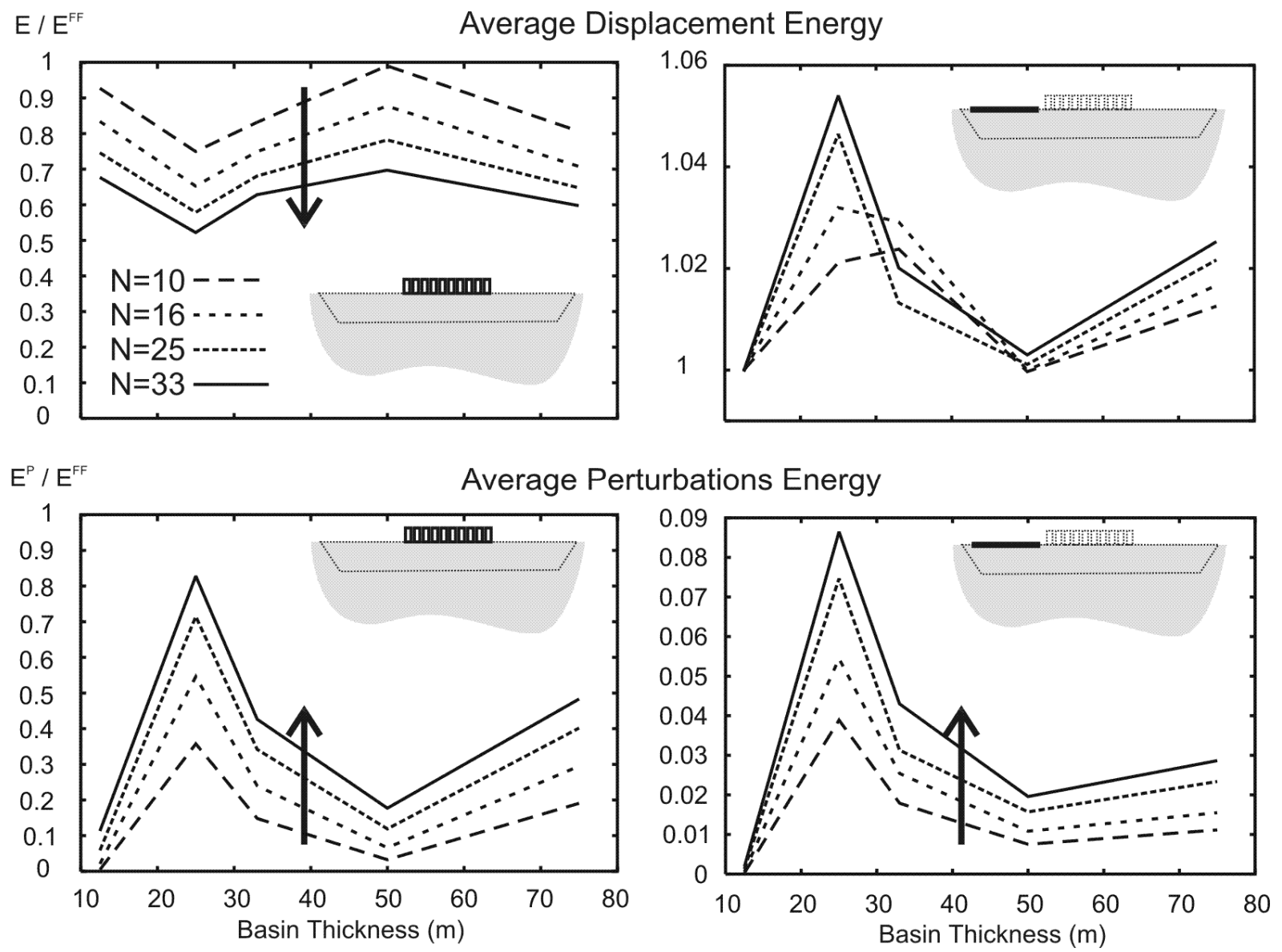

Figure 6: Average ground motion kinetic energy inside (left) and outside (right) the regular city versus thickness normalized by the free-field kinetic energy $\mathrm{E}^{\mathrm{FF}}$ corresponding to the same basin thickness: total kinetic energy $E$ (top) and perturbations kinetic energy $E^{P}$ (bottom). The arrows indicate the increasing number of buildings (urban density). 
These results also indicate that the "single interaction" strategy adopted in early papers by Guéguen et al. $(2000,2002)$ is not valid: waves emitted by each building considered as "single" cannot be added. The site-city interaction is strongly characterized by multiple interaction phenomena. Moreover, these 2D results are consistent with 3D computations by Clouteau at al. (2002), who concluded that multiple interactions are effective for large wavelengths, so that the hypothesis of cumulative single building effect is valid only when the wavelength is small

In addition, outside the city, the total ground motion and perturbation energies vary in the same way: they systematically increase, and the increase is larger for close soil-building frequencies and larger building densities. This increase, however, remains very moderate: the radiated energy $\mathrm{E}^{\mathrm{P}}$ may reach $10 \%$ of the freefield, but the overall ground energy increase does not exceed $5 \%$.

Spatial correlation of the ground motion. The effect of a single structure on the neighbouring soil has two components: the kinematic effect (associated with wave diffraction on the foundation) and the inertial effect (associated with wave emission following building vibrations). In both cases, the wavefield radiated from the foundation propagates horizontally in the layered soil. In the case where many buildings are involved, the individual waves radiated by each building may interfere (multiple interaction), and significantly modify the ground motion pattern along the surface. This pattern may be highlighted by the analysis of the spatial correlation of the ground motion. With that aim, we first define the covariance coefficient $\mathrm{C}$ of the ground motion $\mathrm{u}$ as follows:

$$
\mathrm{C}(\mathrm{r}, \omega)=\frac{\left\langle\mathrm{u}(\mathrm{x}, \omega) \cdot \mathrm{u}^{*}\left(\mathrm{x}^{\prime}, \omega\right)\right\rangle_{\mathrm{r}=\left\|\mathrm{x}-\mathrm{x}^{\prime}\right\|}}{\sqrt{\left\langle\|\mathrm{u}(\mathrm{x}, \omega)\|^{2}\right\rangle\left\langle\left\|\mathrm{u}\left(\mathrm{x}^{\prime}, \omega\right)\right\|^{2}\right\rangle}}
$$

where $\mathrm{u}$ is the displacement, $\mathrm{x}$ and $\mathrm{x}^{\prime}$ the positions, $\mathrm{r}$ the distance $\left\|\mathrm{x}-\mathrm{x}^{\prime}\right\|, \omega$ the frequency, $\left\langle\mathrm{v}\left(\mathrm{x}, \mathrm{x}^{\prime}\right)\right\rangle_{\mathrm{r}}=\frac{1}{\left|\mathrm{I}_{\mathrm{r}}\right|} \sum_{\left(\mathrm{x}, \mathrm{x}^{\prime}\right) \in \mathrm{I}_{\mathrm{r}}} \mathrm{v}$ with $\mathrm{I}_{\mathrm{r}}=\left\{\left(\mathrm{x}, \mathrm{x}^{\prime}\right) /\left\|\mathrm{x}-\mathrm{x}^{\prime}\right\|=\mathrm{r}\right\}$, is the averaging operator, and * the hermitian operator (transposition and conjugation).

The spatial correlation length $\mathrm{L}_{\mathrm{u}}$ may then be defined as:

$$
\mathrm{L}_{\mathrm{u}}(\omega)=\int_{0}^{+\infty} \mathrm{C}(\mathrm{r}, \omega) \mathrm{dr}
$$

where $\omega$ is the frequency and $r$ the distance.

Plotting the variation of the spatial correlation length of ground motion $\mathrm{L}_{\mathrm{u}}$ inside the city for various building density and basin thickness gives the left diagram of Figure 7. The spatial correlation length of the perturbations $\mathrm{L}_{\mathrm{uP}}$ is displayed on the right part of Figure 7.

Two distinct features appear from the spatial correlation versus frequency curves:

1. At $2 \mathrm{~Hz}$, the spatial correlation of ground motion $\mathrm{L}_{\mathrm{u}}$ is lower within the city than on the freefield for close values of soil resonance frequencies (either fundamental or harmonics) and buildings resonance frequencies. The vibration of the buildings alter the ground motion when they are forced into resonance. The decrease of the free-field spatial correlation near the soil resonance frequency is induced by the lateral surface waves generated at the edges of the basin, and is thus strengthened for larger thickness. The presence of the resonating buildings is thus rather unbeneficial since they degrade the spatial correlation, which is especially important for buildings with large foundations. This statement obviously contradicts the homogeneous "group effect" of the resonating buildings, as pointed out in previous considerations. In fact, the ground motion induced by the site-city resonance is also much smaller than that in the free-field, and is therefore much more favourable whatever the motion decorrelation is. 
2. The spatial correlation length of the perturbed wavefield $\mathrm{L}_{\mathrm{uP}}$ shows two distinct features.First, around the soil resonance frequencies $\mathrm{f}_{0}{ }^{\mathrm{s}}$ (fundamental) and $\mathrm{f}_{\mathrm{n}}{ }^{\mathrm{s}}=(2 \mathrm{n}+1) \mathrm{f}_{0} \mathrm{~s}$ (harmonics), $\mathrm{L}_{\mathrm{uP}}$ is high, but very low in between. No clear influence of the building density is visible. The $\mathrm{L}_{\mathrm{uP}}$ variation may be interpreted as previously: at the soil resonance frequencies $\mathrm{f}_{\mathrm{n}} \mathrm{s}$ or when resonance frequencies of both buildings and soil are close (except for the case $\mathrm{H}=33 \mathrm{~m}$ ), the ground perturbations scatter from point to point is globally low. The perturbations are kept uniform because the ground motion is governed by the basin resonance in the first case, and by the homogeneous "group effect" in the second case. Second, when the excitation frequency and the building eigenfrequencies are different from the soil fundamental frequency, as for $\mathrm{H}=50 \mathrm{~m}$, the perturbations amplitude is small and their scatter from point to point is then relatively larger.
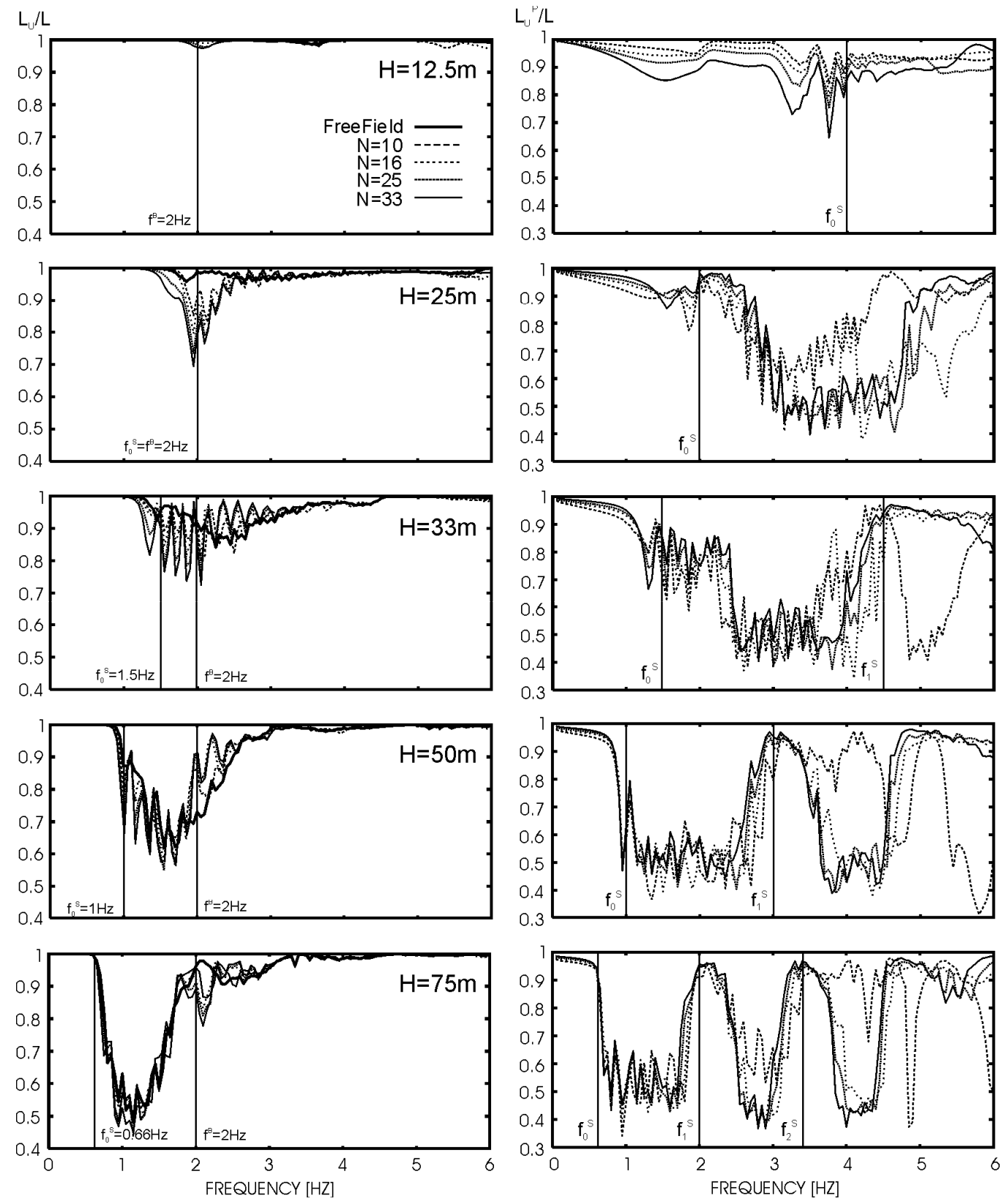

Figure 7: Spatial correlation length of the ground motion $\mathrm{L}_{\mathrm{u}}$ (left) and perturbations $\mathrm{L}_{u p}$ (right) in the regular city model versus frequency for various thicknesses $\mathrm{H}$ and numbers of buildings $\mathrm{N}$. The vertical lines indicate either the soil eigenfrequencies $\mathrm{f}_{0} \mathrm{~S}$ or the B2S building resonant frequency $\mathrm{f}^{\mathrm{B}}=2 \mathrm{~Hz}$. Values of correlation length are normalized by the city width $\mathrm{L}=500 \mathrm{~m}$. 


\section{Results for an Irregular City}

We now consider the case of the irregular city presented in Figure 1. This city is again centered in a basin of various thicknesses $\mathrm{H}$ and is submitted to vertically incident SH waves. The time domain excitation signal is again a second order Ricker wavelet with central frequency $\mathrm{f}^{\mathrm{R}}$.

\section{Response of the city}

Building vibrations. The transfer functions of the two types of buildings are given in Figure 8 and compared with the isolated building case. Since their resonance frequencies are different, B1S and B2S buildings cannot resonate simultaneously. However, it seems that B1S buildings are possibly influenced by the B2S buildings at $2 \mathrm{~Hz}$ for specific basin thicknesses $(\mathrm{H}=25 \mathrm{~m}$ and $75 \mathrm{~m})$. On the contrary, this is less obvious for B2S buildings, because they are barely excited at $1 \mathrm{~Hz}$. This indicates that some interactions between the different buildings may occur with the soil as a coupling medium (structure/soil/structure interaction). To this extent, these interactions may be favoured when several buildings exhibit resonance frequencies close to that of the soil. For instance, Figure 8 shows that the B2S buildings strongly interact with the soil at $2 \mathrm{~Hz}$ for $\mathrm{H}=25 \mathrm{~m}, 33 \mathrm{~m}$ and $75 \mathrm{~m}$, and the B1S buildings at $1 \mathrm{~Hz}$ for $\mathrm{H}=50 \mathrm{~m}$ and $75 \mathrm{~m}$ because of the resonance frequencies coincidence. In such cases, the neighbouring unexcited buildings may be affected to a certain level (Guéguen et al., 2000), which is not obvious on the present transfer functions. This point will be investigated in another article where different city models overlying a two-dimensional basin are considered. These outcomes are actually an additional evidence of the importance of the eigenfrequencies coincidence for SCI.

Perturbations of the ground motion. The irregular arrangement of the city also influences the ground motion. The transfer functions of the perturbations, $\mathrm{u}^{\mathrm{P}}$, displayed in Figure 9, shows several peaks around $1 \mathrm{~Hz}$ and $2 \mathrm{~Hz}$, whereas it is not the case at $1 \mathrm{~Hz}$ for the regular city case (Fig.4). These additional peaks are probably due to B1S buildings, and result in larger ground motion perturbations in case of low frequency excitations. In the present case, ground motion perturbations are thus significant for frequencies around 1 and $2 \mathrm{~Hz}$. One may therefore anticipate that, for densely urbanized cities with building frequencies spanning a wide spectrum, ground motion will also be modified over a wide spectrum. Furthermore, the variability of the building responses is larger than in the regular city case, because of either the presence of other types of buildings (i.e. frequencies) or their irregular arrangement.

Waves radiated by the city. The wave radiation due to the city remains effective despite its irregular nature. One might actually expect that the perturbations induced on the ground by the buildings could be cancelled by destructive interferences. On the contrary, the radiated wavefield keeps a similar amplitude for a $2 \mathrm{~Hz}$ Ricker wavelet, but it is also significantly enhanced for a $1 \mathrm{~Hz}$ Ricker wavelet (Fig.10). In this case as well, the enlargement of the city spectrum plays an important role. Another effect of the city irregularity shown in (Kham, 2004) is the asymmetry of the radiated wavefield, which is stronger on the left handside than on the right handside. This is probably due to the location of the gravity centre of the city (See Figure 1). 

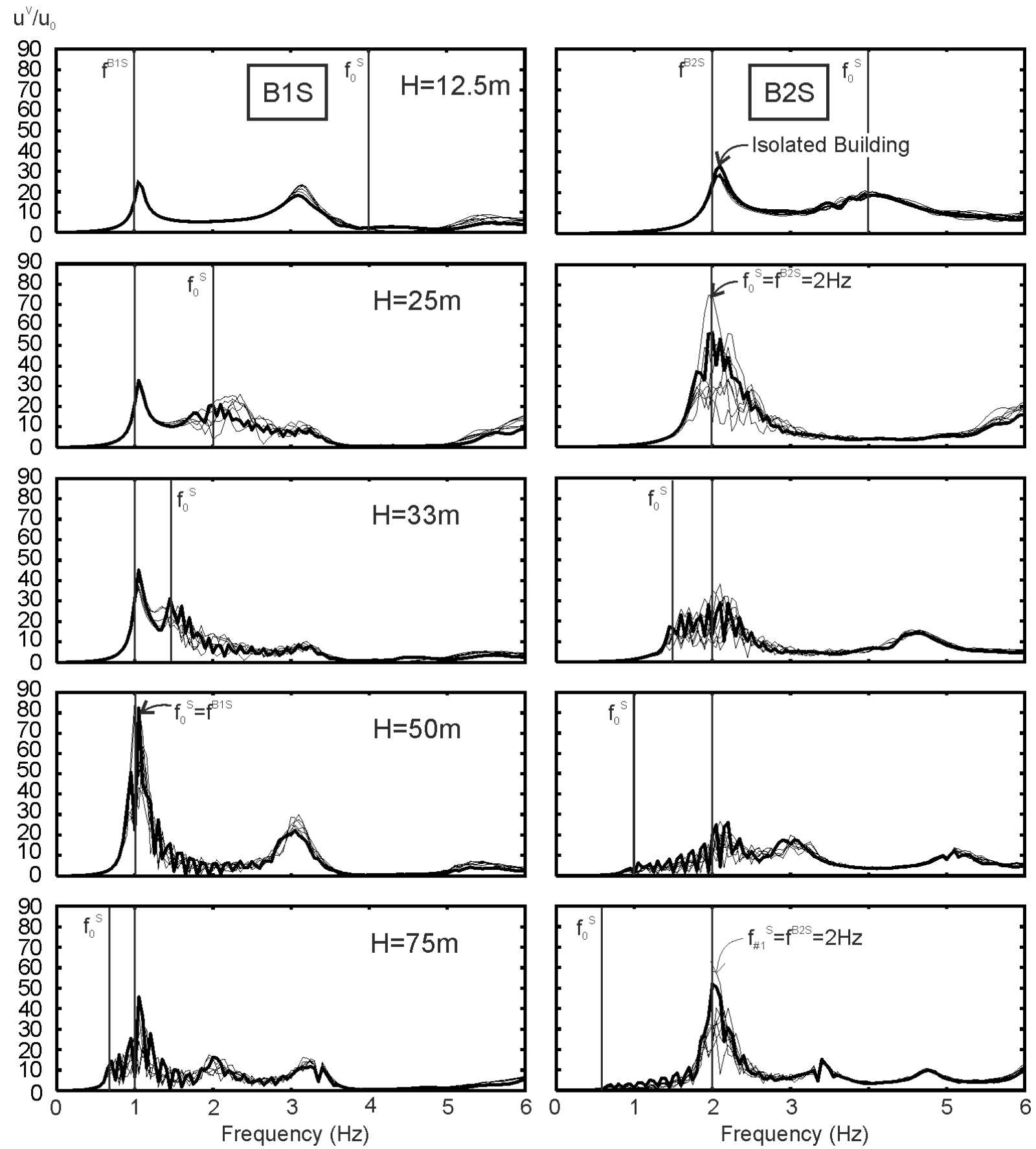

Figure 8: Transfer functions of the buildings vibrations in the irregular city model for B1S buildings (left) and B2S buildings (right). The vertical lines indicate either the soil eigenfrequencies $\mathrm{f}_{0}{ }^{\mathrm{S}}$ or the building resonant frequency $\mathrm{f}^{\mathrm{B}}$. 

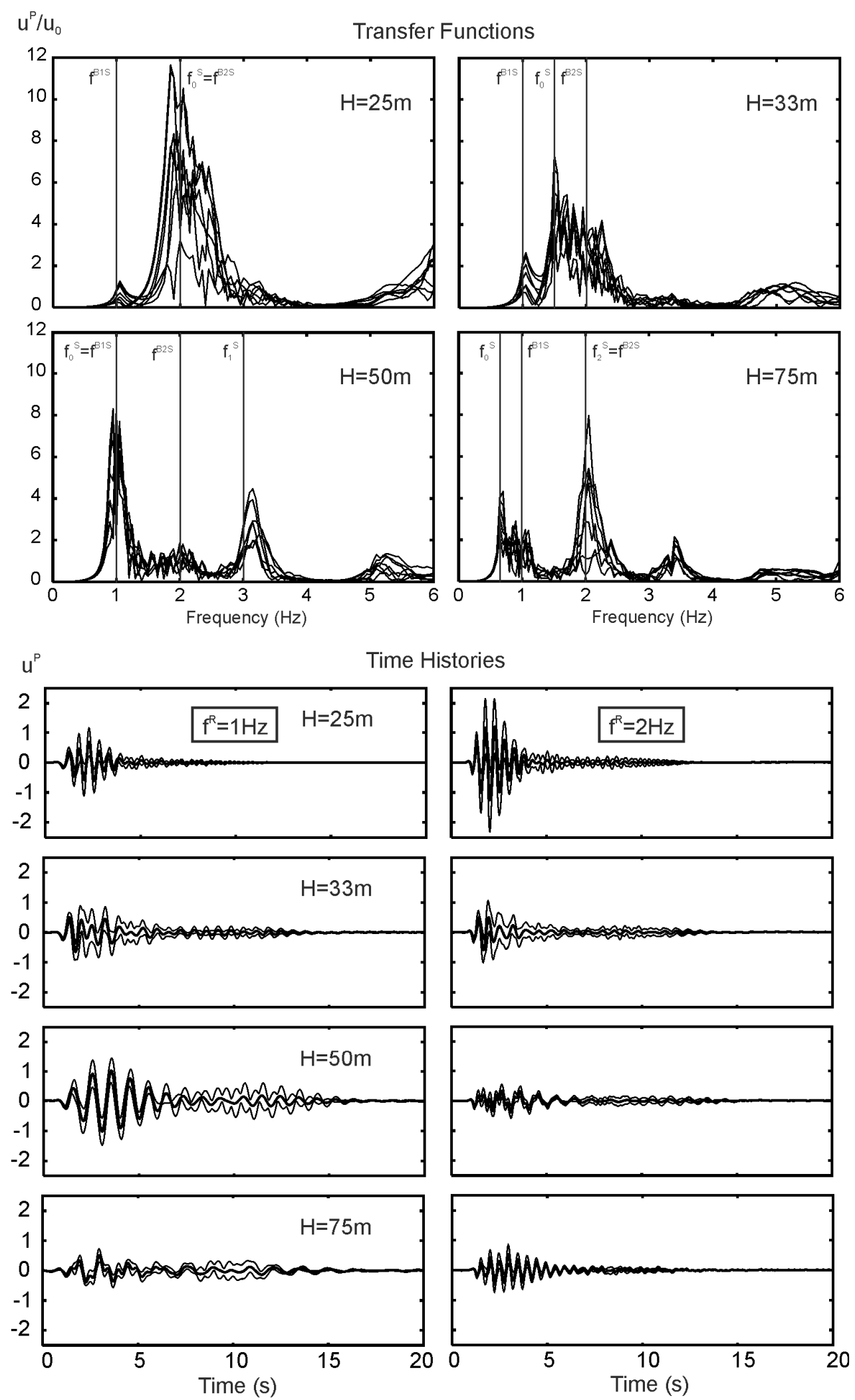

Figure 9: Perturbations of the ground motion in the irregular city model: transfer functions (top) and synthetics under a Ricker wavelet of central frequency $f^{R}$ (bottom). 
$f^{\mathrm{R}}=1 \mathrm{~Hz}$

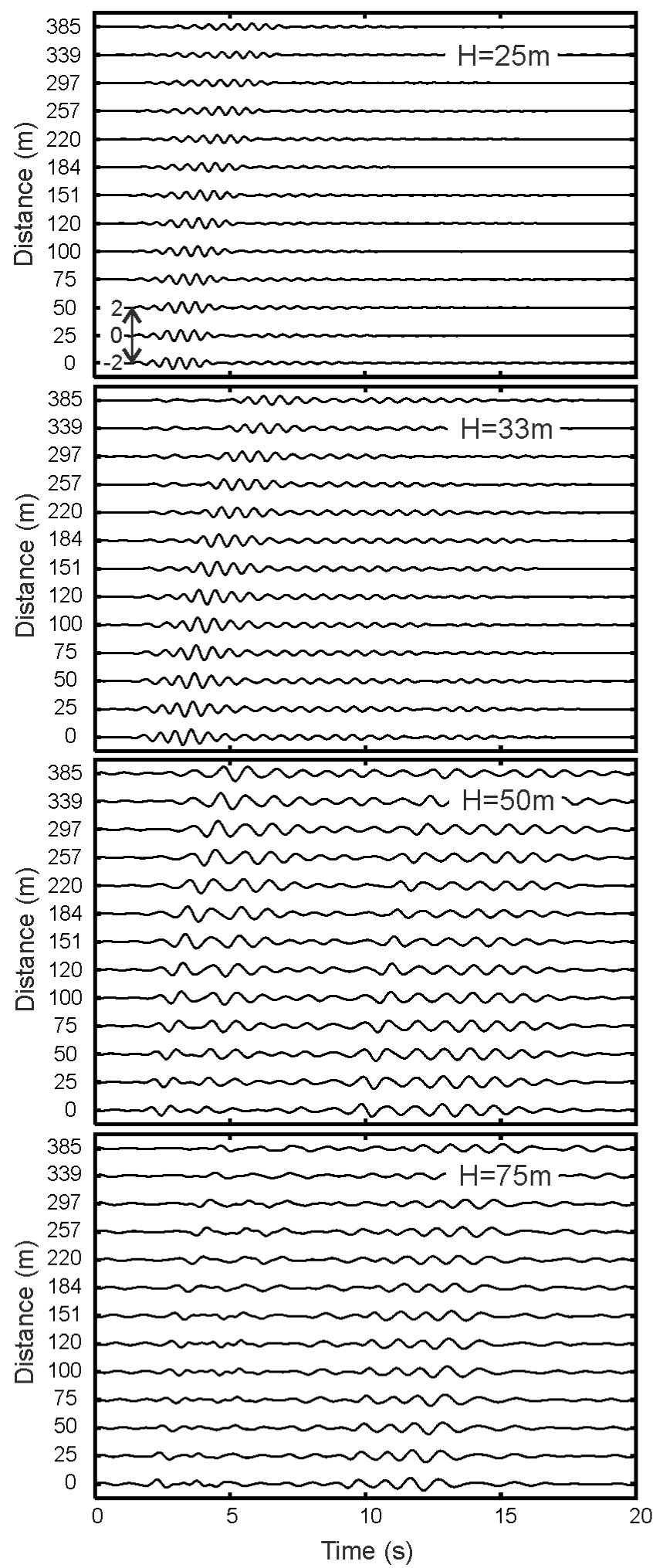

$f^{R}=2 H z$

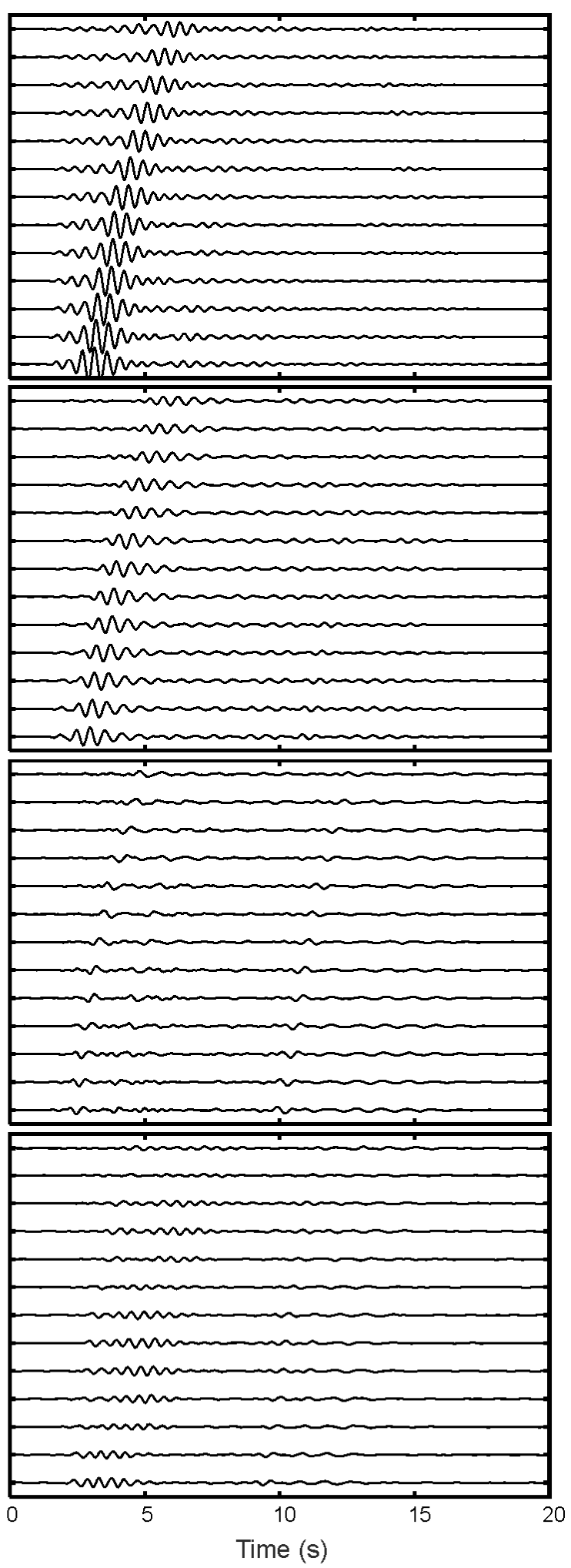

Figure 10: Wavefield radiated outside the irregular city (left handside, area $\mathbf{O}$ ) for various thicknesses and a Ricker wavelet of central frequency $\mathrm{f}^{\mathrm{R}}=1 \mathrm{~Hz}$ (left) and $2 \mathrm{~Hz}$ (right). Wave amplitude scale corresponds to 2 from one trace to another. We recall that the incident wave amplitude is $A_{0}=2$. 


\section{Influence on the freefield ground motion}

Spatial correlation of the ground motion. On the left part of Figure 11, we compare the spatial correlation length inside the regular and the irregular city. The number of buildings $\mathrm{N}$ considered in the regular case is equal to 16 in order to be equivalent to that of the irregular city. As in the regular city case, the spatial correlation length of the ground motion $\mathrm{L}_{\mathrm{u}}$ tends to decrease at $1 \mathrm{~Hz}$ and $2 \mathrm{~Hz}$ when compared to the free-field values. For $\mathrm{H}=50 \mathrm{~m}$, the decrease is rather strong at $1 \mathrm{~Hz}$, where the influence of B1S buildings appears clearly. Moreover, the spatial correlation decrease is generally larger than for the regular city. This is clearly correlated to both the geometrical dissymmetry and the buildings heterogeneity for the irregular city. The latter is obvious on the variation of the perturbations correlation length $\mathrm{L}_{u}{ }^{\mathrm{P}}$ compared to the regular city case (Figure 11, right): large values of $\mathrm{L}_{\mathrm{u}}{ }^{\mathrm{P}}$ are no longer visible at the soil resonance frequencies. One should notice that even at the soil resonant frequency $\mathrm{f}_{0} \mathrm{~S}, \mathrm{~L}_{\mathrm{u}}{ }^{\mathrm{P}}$ is now shortened. Such a feature clearly shows the strong variablility of the ground motion for the irregular city. It may be an interesting goal for future experimental measurements to put forward some evidences of SCI.

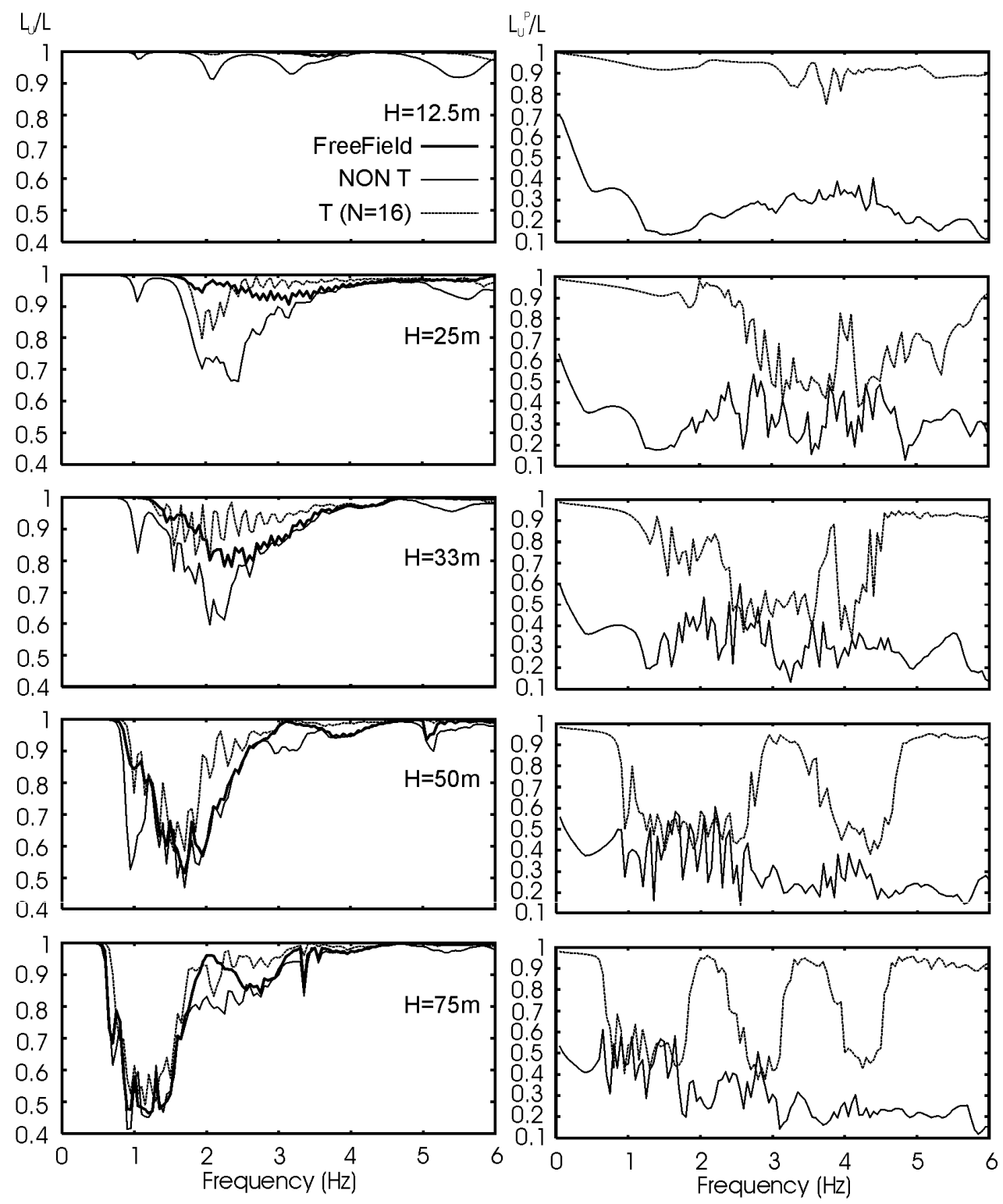

Figure 11: Spatial correlation length of ground motion $\mathrm{L}_{\mathrm{u}}$ (left) and perturbations $\mathrm{L}_{\mathrm{up}}$ (right) inside the irregular city. Comparison with the freefield (thick line) and the regular city case with a similar number of buildings $\mathrm{N}=16$ (dotted line). 
Ground shaking energy. At the bottom of Figure 12, the variation of energy inside and outside the city is displayed for different thicknesses. Whatever the signal input dominant frequency, the ground motion energy $\mathrm{E}$ inside the city is decreased in average when compared to the freefield. This is consistent with the previous regular city case and it also leads to a symmetrical increase of the perturbations energy $E^{P}$. However, the maximum energy decrease is now reached for the two basin thicknesses $(\mathrm{H}=25 \mathrm{~m}$ and $50 \mathrm{~m})$ corresponding to the coincidence between the soil and the two buildings resonance frequencies $(2 \mathrm{~Hz}$ and $1 \mathrm{~Hz}$, respectively). A more detailed analysis of the energy distribution within the city (top of Figure 12) reveals a very irregular pattern, rather different from the regular city case, with two remarkable features:

1. the ground motion variability exceeds $50 \%$ and it may partly explain the large damage variability observed during some destructive earthquakes (despite homogeneous and close blocks).

2. the total ground motion energy $\mathrm{E}$ may be locally larger than the free-field energy $\mathrm{E}^{\mathrm{FF}}$. Given the limited number of investigated cases, it is difficult to derive simple rules to characterize the areas where the ground motion might be amplified depending on the city configuration. However, a trend for an increase in ground motion energy may be detected at the outskirts of dense areas. Let us point out the following areas: around $\mathrm{x}=-200$ and $\mathrm{x}=-50 \mathrm{~m}$ at $1 \mathrm{~Hz}$, on each side of a group of three B1S buildings ; around $x=-150 \mathrm{~m}$ at $2 \mathrm{~Hz}$, on the left side of a group of three B2S buildings.
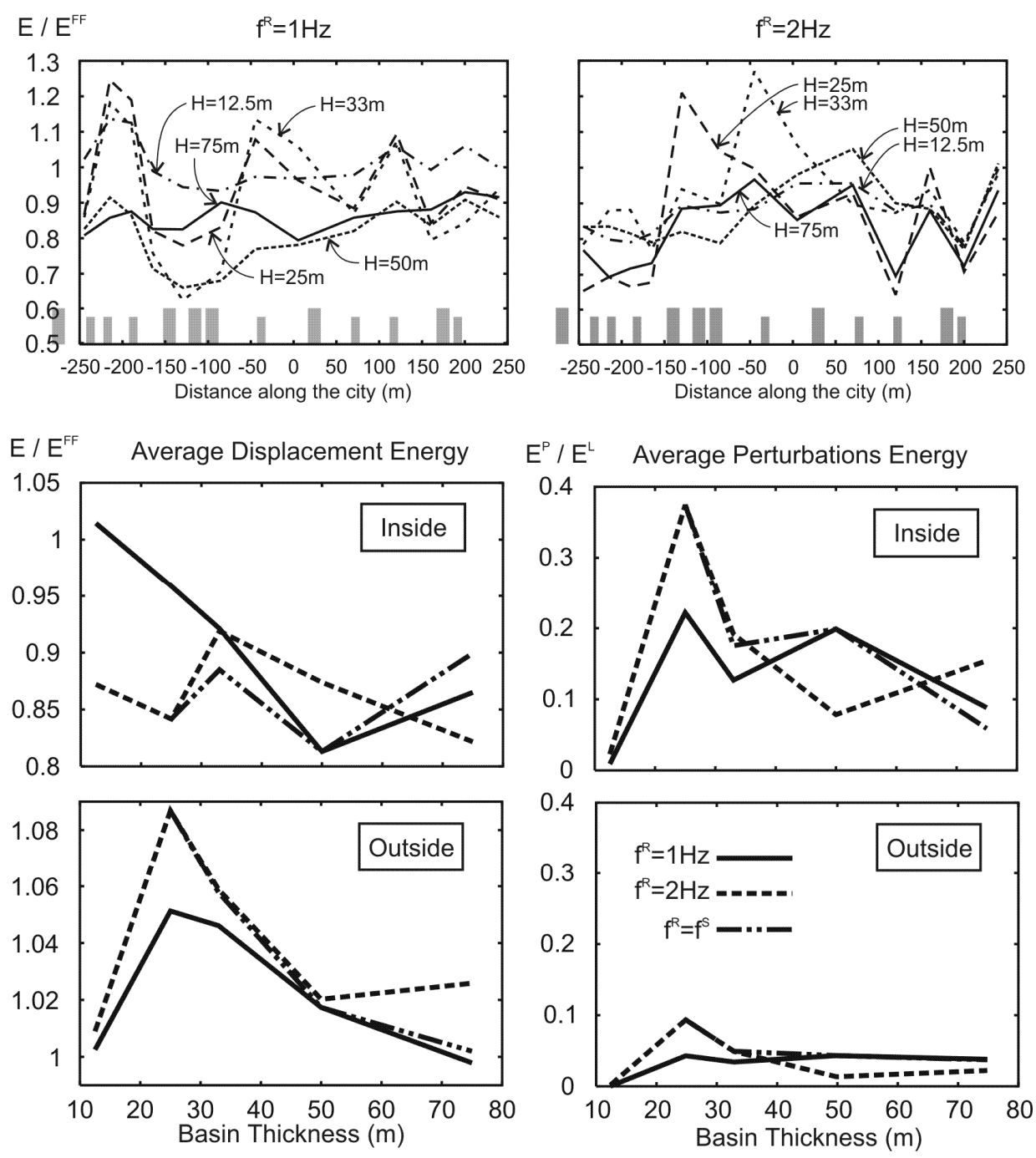

Figure 12: Ground motion energy variation along the irregular city for various thicknesses $H$ (top). Normalized average energy of the ground motion versus thickness inside and outside the irregular city (middle and bottom): total kinetic energy $\mathrm{E}$ (left) and perturbations kinetic energy $\mathrm{E}^{\mathrm{P}}$ (right). 


\section{Comparison with the case of a homogeneous irregular city.}

In this paragraph, we finally propose a comparison between the previous heterogeneous irregular city case and a homogeneous irregular city arrangement. For this purpose, we replace the B1S buildings (resonating at $1 \mathrm{~Hz}$ ) in the heterogeneous city by B2S buildings (resonating at $2 \mathrm{~Hz}$ ), but keep the location of all buildings. We thus get an intermediate case between the homogeneous and periodic city of section 3 (only the building arrangement has been changed), and the previous heterogeneous and unperiodic city. On the left of Figure 13, we thus compare the so-called vibration energy of the buildings (top) - defined as the kinetic energy (Eq.1) of the relative motion between the building top and its base - and the surface kinetic energy inside the city (bottom). This comparison is made for the homogeneous and heterogeneous cities and for the with a layer thickness $\mathrm{H}=25 \mathrm{~m}\left(\mathrm{f}_{0}{ }^{\mathrm{S}}=2 \mathrm{~Hz}\right)$ subjected to a Ricker pulse of central frequency $\mathrm{f}^{\mathrm{R}}=2 \mathrm{~Hz}$. We also show on the right handside of Figure 13 the vibration energy in the homogeneous and periodic city of section 3 for different building densities, and for the same basin configuration and Ricker frequency. Unlike the previous curves, the energy value corresponds to the absolute value. Namely, the free-field kinetic energy is about $\mathrm{E}^{\mathrm{FF}}=4.7 .10^{4}$.

These results yield several important remarks:

- The surface kinetic energy decreases in both cases: $\mathrm{E}<\mathrm{E}^{\mathrm{FF}} \approx 4.710^{4}$ (bottom of Figure 13). The decrease is however stronger for the homogeneous than for the heterogeneous city, and is in average about $\mathrm{E}_{\mathrm{hom}} \approx 3.5 .10^{4}$. It corresponds to the same level as in the periodic city with equivalent numbers of buildings $10<\mathrm{N}<16$ (Fig.6). But unlike the periodic city, the energy distribution changes with alternating peaks and troughs. Troughs seems to be located in the dense area ($250 \leq x \leq 0$ ), where the group effect is stronger. The only loss in periodicity thus induces a loss in uniformity of surface motion inside the city.

- The surface kinetic energy is lower in the homogeneous case than in the heterogeneous case. The B1S buildings may induce larger energy peaks than in the free-field case (for example, at $x=-150 \mathrm{~m}$, Figure 13, bottom). B1S buildings do not resonate, as shown by their vibration energy (top-left of Figure 13). In fact, they react as rigid masses perturbing the soil motion by their inertial effect (their fundamental frequency is much lower than the Ricker central frequency). We thus may think that the larger their mass, the stronger the irregularity of the surface motion, with potential appearance of strong energy peaks.

- The vibration energy decreases significantly in the non periodic cities compared to the periodic city (top of Figure 13). The loss of symmetry in the city weakens the building group effect (site-city resonance). This fact can be interpreted intuitively by lateral interferences due to the "path difference" from one building to another. In the heterogeneous city, it is clear that the B1S buildings do not resonate (energy troughs).

With this intermediate model, we thus understand more clearly the respective influence of irregularity and heterogeneity on the modification of site-city interaction. Namely, the irregularity weakens the building group effect (global resonance) inducing a lower ground motion decrease, while the heterogeneity tends to reinforce the non-uniformity of ground motion, and strong ground energy focusing. This focusing may be more dangerous for a light building, while for a massive building the issue is not so clear since it may itself interact with the soil and modify the site-city interactions. In our sense, we should consider at this stage more realistic geological models to take into account at the same time the lateral heterogeneities in the soil. furthermore we are perhaps reaching here the limit of a deterministic analysis of the SCI. 

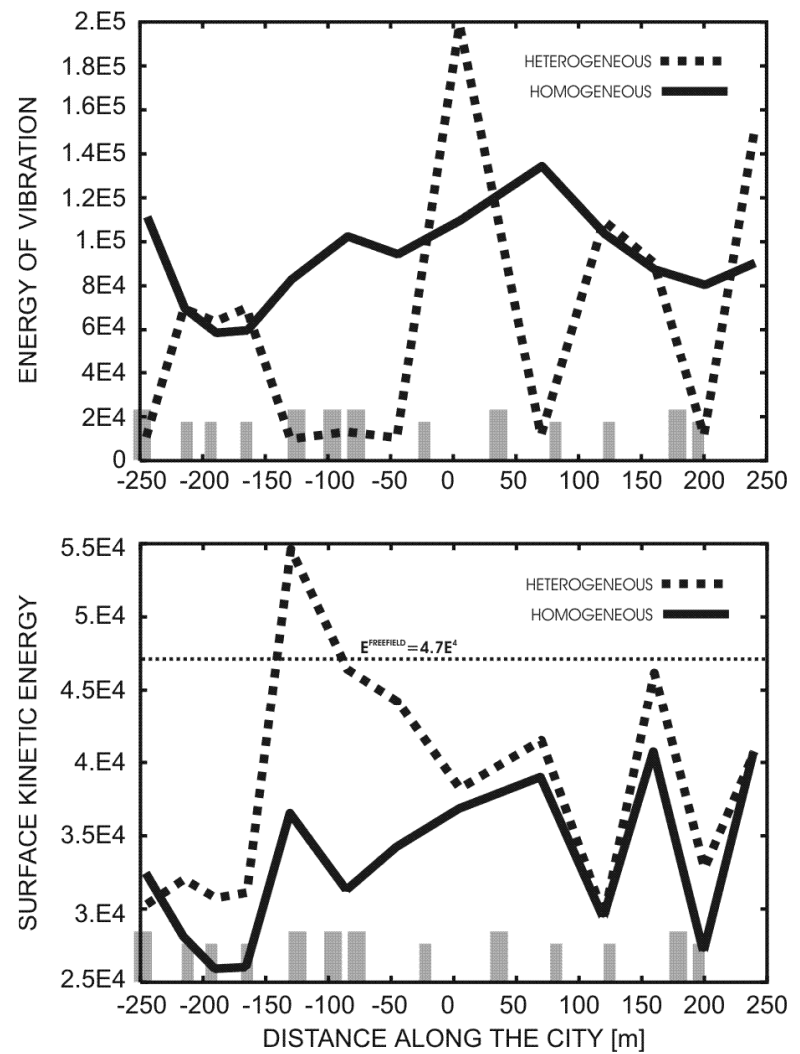

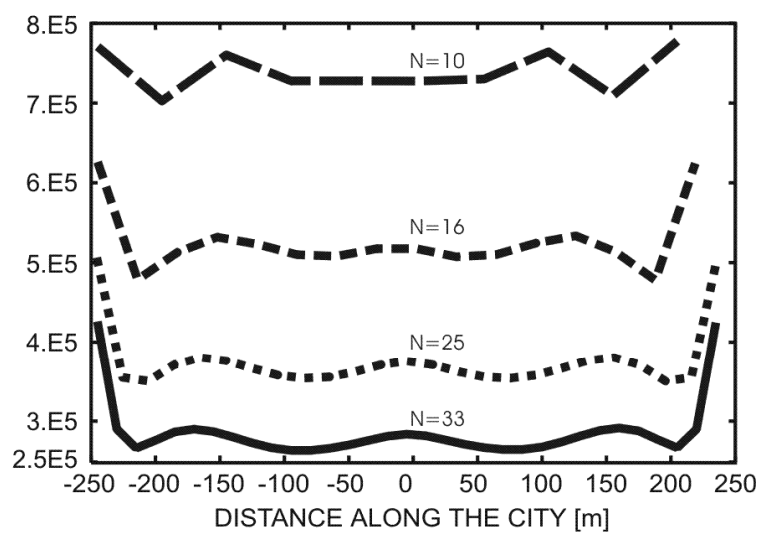

DISTANCE ALONG THE CITY [m]

Figure 13: Top) Energy of building vibration along the non-periodic (left) and periodic (right) cities for the homogeneous and inhomogeneous urban configurations in the first case, and for different numbers of buildings in the second case. Bottom) Surface kinetic energy along the non-periodic city for the homogeneous and inhomogeneous urban configurations. Solutions are computed for basin thickness $\mathrm{H}$ $=25 \mathrm{~m}\left(\mathrm{f}_{0}{ }^{\mathrm{S}}=2 \mathrm{~Hz}\right)$ and a Ricker frequency $\mathrm{f}^{\mathrm{R}}=2 \mathrm{~Hz}$. Energy values are absolute values. A straight line in the bottom graph marks the freefield kinetic energy level.

\section{The Site-City Response under Incident SV Waves}

All the results presented in previous sections were derived for antiplane motion, i.e., for incident SH waves. One may wonder if they hold for in-plane motion. In that case, the buildings are allowed to rock, and one may thus expect significant changes of SCI phenomena due to differences in the buildings response and in waves diffraction at their bases (more complex wave propagation phenomena for in plane motion). In order to compare the results in both the SH and SV cases, we performed similar computations for incident SV waves (same types of deposits with various constants thicknesses, same regular and irregular cities, same incident signals). The whole results are detailed in (Kham, 2004), and are only briefly summarized in this section.

First of all, the main characteristics of SCI outlined in the SH case still stand in the SV case. A "group effect" (multiple interactions) is activated when the soil and buildings resonance frequencies coincide., This is globally beneficial in terms of ground motion since the ground shaking energy decreases inside the city. Surface waves are radiated outwards by the city when the site-city system resonates. The spatial coherency of the ground motion is reduced inside the city, especially when irregularity is introduced in the city arrangement.

These identical features are nevertheless modulated by several remarkable differences:

- The duration of the building relative horizontal motions $\mathrm{u}^{\mathrm{V}}=\mathrm{u}^{\mathrm{S}}-\mathrm{u}^{\mathrm{P}}$ increases, probably because the rocking enabled by SSI does not perfectly involve the shear structural damping of the building 
(Bard, 1988). This duration lengthening occurs mainly for low urban densities $(\theta \leq 0.2)$. For higher densities, the buildings vibrations in the regular city show insignificant differences when compared to the SH case. This effect is probably due to the building group effect which counteracts the free oscillations of each single structure.

- Consequently, the global group effect on the ground motion also decreases for low densities $(\theta \leq 0.2)$, since the amount of incident seismic energy dissipated by the buildings is lower.

- The ground energy decrease is similar in average inside both the regular city $\left(\mathrm{E} / \mathrm{E}^{\mathrm{FF}} \rightarrow 0.6\right)$ and the irregular city $\left(\mathrm{E} / \mathrm{E}^{\mathrm{FF}} \rightarrow 0.7\right)$. However, the energy distribution inside the irregular city is more uniform in the SV case than in the SH case. Such an effect may be due to the building densities of B1S and B2S buildings groups which are respectively lower than $\theta=0.2$.

- Within the irregular city, the spatial coherency of the ground motion is larger for the SV case than for the SH case. This may also be due to the more important role of the building density in the group effect.

\section{Conclusions}

In this work, we have attempted to derive the main features of Site-City Interaction (SCI) through simplified two-dimensional basin-city models taking into account the multiple interactions between buildings. Varying the basin thickness and the buildings density allowed better capturing the main parameters controlling SCI. The main results for a regular city are:

- When the soil frequencies match the building frequency, i.e., when the soil/structure coupling is strong, the building vibrations are more easily transmitted to the ground and it induces a significant perturbation of the freefield ground motion. At the same time, the buildings top motion is reduced with respect to the single building case.

- The ground motion induced by each building modifies the motion of the other buildings through the whole system. These multiple interactions are really effective when the site-city resonance occurs. It produces a homogeneous group effect of the whole building set, leading to a significant ground motion reduction inside the city. In such a case, the energy of the ground motion may be decreased by nearly $50 \%$.

- The increase of the building density tends to enhance the group effect and the ground motion reduction. For example, a building density increase from $\theta=0.2$ to 0.66 leads to an energy decrease ranging from $20 \%$ to $50 \%$ (Fig. 6 )

- On the contrary, the ground motion energy outside the city increases, due to the strengthening of the wavefield radiated by the city (mainly surface waves). The energy of the radiated waves may reach $10 \%$ of the freefield motion.

In the case of the irregular city with two building types and variable spacing, two apparently opposite effects appear:

- Since the city spectral response is broadened with the resonance frequencies of both building types, the site-city frequency coincidence is more frequent and SCI resonance bandwidth is enlarged.

- However, the irregularity of the city, due to both the different building types and their non periodical arrangement, influences the group effect since it reduces the coherency of the buildings response. This effect results in a stronger decrease of the spatial correlation of the ground motion when compared to the regular city case. 
At some specific locations inside the irregular city, the loss of coherency may also result in constructive interferences between perturbations, giving rise to a larger ground motion. These local peaks may reach $30 \%$ of the freefield ground motion energy, and the site to site energy variability may reach $50 \%$.

Such results should be considered as a first attempt to discuss the origin of SCI and characterize its basic features, which in turn can provide guidelines for further investigations and give accurate tools to quantitatively assess the impact of SCI. As a matter of fact, this work confirms the results of several previous works, stating that the built environment in a city may, in some specific conditions, significantly modify the "freefield" ground motion. Since the buildings response is very different from that of a single building and since multiple interactions are involved, SCI produces a global effect which can really be strong and is therefore almost unpredictable with usual methods. Moreover, the results also point out some potential guidelines for the experimental assesment of SCI: for example, one may now imagine specific tools and methods in order to measure the spatial coherency inside cities, or to detect and characterize the wavefield diffracted outside the city. For instance, one may compare the results at various periods of time (influence of new constructions...). Most of all, if this series of numerical results gives sufficient evidences of SCI, it may significantly change common interpretations about the urban seismic hazard and risk. Although essentially beneficial, SCI may for example explain, together with "classical" site-effects, the variability in the damages distribution usually observed inside apparently homogeneous buildings blocks.

However, our numerical models do have some limitations, and call for great caution in extrapolating their results, mostly due to large simplifications for both the building and the soil models. Although leading to similar qualitative conclusions for the major characteristics of SCI, simulations already show some non negligible differences between the SH and SV cases, mainly due to the buildings response: namely, the important role of the building density on the group effect is strengthened in the SV case... This simple point raises the question of the buildings model validity: since the buildings response is controlling SCI, will the same conclusions hold for more realistic building models, taking into account the mass and stiffness distribution of the buildings, their foundations or more generally their 3D translational and rotational responses? Moreover, the basin model is also questionable: in many cases, the soil layers under the city cannot be considered as one dimensional. In actual geological structures, the lateral depth variation of the soil layers makes the assumption of the vertical resonance of a 1D layer irrelevant (e.g. 2D/3D alluvial basins). Particularly, surface waves involved in site amplification may propagate across the city (Bard and Bouchon, 1985, Bielak et al., 1999, Chammas et al. 2003, Sánchez-Sesma and Luzon, 1995, Semblat et al., 2000, 2003, 2005). What is the site-city interaction in such a case? It thus seems that the question of SCI will remain uncompleted as long as these questions have not been seriously considered.

\section{Acknowledgements}

We would like to acknowledge the team of the French national project ACI CATNAT on seismic hazard in urban areas in the framework of which this work was made possible. We would like to thank Philippe Guéguen for his pioneering work on the SCI, which was the starting point of our numerical investigations.

We would also like to thank the reviewers, as well as the associate editor, for their valuable comments on the preliminary version of this article.

\section{References}

Bard, P-Y. (1988). The importance of rocking in building motion: an experimental evidence, Proc. of the $9^{\text {th }}$ World Conference on Earthquake Eng., Tokyo-Kyoto, VIII, 333-338, august 2-9. 
Bard, P-Y., Bouchon, M. (1985). The two dimensional resonance of sediment filled valleys, Bull. Seism. Soc. Am., 75, 519541.

Bielak J., Xu J., Ghattas O. (1999). Earthquake ground motion and structural response in alluvial valleys, J. Geotech. Geoenviron. Eng., 125, 413-423.

Bonnet, M. (1999). Boundary integral equation methods for solids and fluids, Wiley, Chichester, UK.

Boutin, C., Roussillon, P. (2004). Assessment of the urbanization effect on seismic response, Bull. Seism. Soc. Am., 94, no. 1, 251-268.

Chammas R., O.Abraham, P.Cote, H.Pedersen, J.F.Semblat (2003). Characterization of heterogeneous soils using surface waves : homogenization and numerical modeling, Int. Jal Geomechanics (ASCE), 3, no. 1, 55-63.

Chávez-García F.J., M. Cárdenas-Soto (2002). The contribution of the built environment to the freefield ground motion in Mexico city, Soil Dyn. Earthquake Eng., 22, 773-780.

Chazelas, J.L., PH. Guéguen, P-Y. Bard, J-F. Semblat (2003). Modeling of the site-city effect with centrifuge small scale model (instrumental techniques validation) (in French), $6^{\text {th }}$ National Conference on Earthquake Eng. (AFPS 2003), I, 245-252, Palaiseau, France.

Clouteau D., D. Aubry (2001). Modification of ground motion in dense urban areas, J. Comput. Acoust., 6, 1659-1675.

Clouteau D., O. Ishizawa and N. Mezher (2002). Seismic wave propagation in a random city, 7th National Conf. on Earthquake Eng., Boston.

Dangla P., Semblat J-F., Xiao H.H., Delépine N. (2005). A Simple and Efficient Regularization Method for 3D BEM: Application to Frequency-Domain Elastodynamics, Bull. Seism. Soc. Am., 95, no.5, 1916-1927.

Dangla, P. (1988). A plane strain soil-structure interaction model, Earthquake Eng. Struct. Dyn., 16, 1115-1128,

Erlingsson, S. and A. Bodare (1996). Live load induced vibrations in Ullevi stadium - Dynamic soil analysis, Soil Dyn. Earthquake Eng., 15, 171-188.

Erlingsson, S. (1999). Three-dimensional dynamic soil analysis of a lived load in Ullevi stadium, Soil Dyn. Earthquake Eng., 18, 373-386.

Guéguen, P., P.-Y. Bard and F.J. Chávez-García (2002). Site-City Interaction in Mexico City-Like environments: An Analytical Study, Bull. Seism. Soc. Am., 92, no.2, 794-811.

Guéguen P. (2000). Seismic Interaction between soil and buildings: from Soil-Structure Interaction to Site-City Interaction, $\mathrm{PhD}$ thesis (in French), University of Grenoble, France.

Guéguen P., P-Y. Bard, C.S. Oliveira (2000) Experimental and numerical analysis of soil motions caused by free vibrations of a building model, Bull. Seism. Soc. Am., 90, no.6, 2037-2043.

Jennings P.C. (1970). Distant motions from a building vibration test, Bull. Seism. Soc. Am., 60, 2037-2043.

Kham M. (2004). Seismic wave propagation in alluvial basins: from site effects to site-city interaction (in French), $\mathrm{PhD}$ thesis, École Nationale des Ponts et Chaussées, Paris.

Mezher N. (2004). Numerical Modelling and quantification of the site-city seismic effect (in French), PhD Thesis, École Centrale Paris, France.

Sánchez-Sesma F.J. and F. Luzon (1995). Seismic response of three-dimensional alluvial valleys for incident P, S and Rayleigh waves, Bull. Seism. Soc. Am., 85, 269-284.

Semblat J.F., M.Kham, E.Parara, P.Y.Bard, K.Pitilakis, K.Makra, D.Raptakis (2005). Site effects : basin geometry vs soil layering, Soil Dyn. Earthquake Eng., 25, no.7-10, 529-538.

Semblat J.F., R.Paolucci, A.M.Duval (2003). Simplified vibratory characterization of alluvial basins, Comptes-Rendus Geoscience, 335, no.4, 365-370.

Semblat J-F., P. Dangla, M. Kham, A-M. Duval (2002a). Seismic site effects for shallow and deep alluvial basins: in-depth motion and focusing effect, Soil Dyn. Earthquake Eng., 22, no.9-12, 849-854.

Semblat J-F., M. Kham, P. Guéguen, P-Y. Bard, A-M. Duval (2002b). Site-city interaction through modifications of site effects, $7^{\text {th }}$ US Conference on Earthquake Eng., Boston.

Semblat J-F., A-M. Duval, P. Dangla (2000). Numerical analysis of seismic wave amplification in Nice (France) and comparisons with experiments, Soil Dyn. Earthquake Eng., 19, no.5, 347-362.

Semblat, J-F., Luong, M.P. (1998). Wave propagation through soils in centrifuge experiments, Jal Earthquake Eng., 2, no.1, $147-171$.

Tsogka, C., Wirgin A. (2003). Simulation of seismic response in an idealized city, Soil Dyn. Earthquake Eng., 23, 391-402.

Wirgin A., P-Y. Bard (1996). Effects of buildings on the duration and amplitude of ground motion in Mexico city, Bull. Seism. Soc. Am., 86, no.3, 914-920. 